ORIGINAL ARTICLE / ARTIGO ORIGINAL

\title{
The effect of prevention methods on reducing sexual risk for HIV and their potential impact on a large-scale: a literature review
}

\author{
O efeito dos métodos preventivos na redução do risco de infecção pelo \\ HIV nas relações sexuais e seu potencial impacto em âmbito populacional: \\ uma revisão da literatura
}

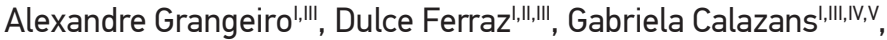
Eliana Miura Zucchill,VI, Ximena Pamela Díaz-Bermúdez ${ }^{\mathrm{VII}}$
\end{abstract}

\begin{abstract}
A spectrum of diverse prevention methods that offer high protection against HIV has posed the following challenge: how can national AIDS policies with high coverage for prevention and treatment make the best use of new methods so as to reverse the current high, and even rising, incidence rates among specific social groups? We conducted a narrative review of the literature to examine the prevention methods and the structural interventions that can have a higher impact on incidence rates in the context of socially and geographically concentrated epidemics. Evidence on the protective effect of the methods against sexual exposure to HIV, as well as their limits and potential, is discussed. The availability and effectiveness of prevention methods have been hindered by structural and psychosocial barriers such as obstacles to adherence, inconsistent use over time, or only when individuals perceive themselves at higher risk. The most affected individuals and social groups have presented limited or absence of use of methods as this is moderated by values, prevention needs, and life circumstances. As a result, a substantial impact on the epidemic cannot be achieved by one method alone. Programs based on the complementarity of methods, the psychosocial aspects affecting their use and the mitigation of structural barriers may have the highest impact on incidence rates, especially if participation and community mobilization are part of their planning and implementation.
\end{abstract}

Keywords: HIV. Prevention \& control. Condom. HIV Serosorting. Pre-exposure prophylaxis. Post-exposure prophylaxis.

'Department of Preventive Medicine, School of Medicine, Universidade de São Paulo - São Paulo (SP), Brazil.

"Regional Board of Brasília, Escola Fundação Oswaldo Cruz de Governo - Brasília (DF), Brazil.

"'Study Group for AIDS prevention, Universidade de São Paulo - São Paulo (SP), Brazil.

Iv Public Health Department, School of Medical Sciences at Santa Casa de São Paulo - São Paulo (SP), Brazil.

v'Regional Center Health Coordinating Office, Municipal Secretariat of Health, São Paulo City Hall - São Paulo (SP), Brazil.

v'Graduate Program on Public Health, Universidade Católica de Santos - Santos (SP), Brazil.

vinepartment of Public Health, Universidade de Brasília - Brasília (DF), Brazil.

Corresponding author: Alexandre Grangeiro. Departamento de Medicina Preventiva, Faculdade de Medicina, Universidade de São Paulo, Avenida Doutor Arnaldo, 455, $2^{\circ}$ Andar, Pinheiros, CEP: 01246-903, São Paulo, SP, Brasil. E-mail: ale.grangeiro@gmail.com

Conflict of interests: nothing to declare - Financial support: none. 
RESUMO: A existência de diferentes métodos preventivos que oferecem elevado grau de proteção contra o HIV tem trazido à luz um desafio: como países que proporcionaram ampla cobertura de prevenção e tratamento poderão utilizar novos métodos preventivos para reverter taxas de incidência que permanecem elevadas, até mesmo crescentes, em grupos sociais específicos? Realizamos uma revisão narrativa da literatura com a finalidade de examinar os métodos preventivos e as intervenções estruturais que, no contexto de epidemias concentradas populacional e geograficamente, podem ter maior impacto nas taxas de incidência. Com isso, analisamos o conhecimento acerca do grau de proteção dos diferentes métodos, seus limites e suas potencialidades. O alcance e a efetividade dos métodos têm sido minimizados, notadamente, por barreiras estruturais e psicossociais, como falhas de adesão, uso inconsistente ao longo do tempo ou apenas em situações em que as pessoas se percebem em maior risco. Indivíduos e grupos sociais mais atingidos pela epidemia têm limitado o uso e o não uso de métodos de acordo com seus valores, necessidades identificadas de prevenção e condições de vida. Isso impede que um método isoladamente venha a promover um forte impacto de redução na epidemia. Políticas baseadas na oferta conjunta e na complementaridade entre os métodos, na atenção aos aspectos psicossociais que interferem no seu uso e na redução das barreiras estruturais de acesso poderão ter maior impacto na incidência, especialmente se forem planejadas e implantadas com participação e mobilização social.

Palavras-chave: HIV. Prevenção \& controle. Preservativo. Seleção por Sorologia para HIV. Profilaxia pré-exposição. Profilaxia pós-exposição.

\section{INTRODUCTION}

The analysis of the AIDS tendency in Brazil indicates the aggravation of the epidemic ${ }^{1}$, marked by the highest incidence rates of the diseases in the past 30 years; by the increasing number of cases among homosexuals and young people; by high HIV prevalence rates in specific populations; and by characteristics of generalized epidemics in cities from the South and North regions. On the other hand, a set of new efficient methods to prevent the sexual transmission of HIV has created global enthusiasm for bringing real opportunities to control the epidemic in different contexts ${ }^{2}$. Much of this enthusiasm comes from methods based on antiretroviral therapy (ART) $)^{3}$, which have proven to be able to prevent the acquisition and transmission of HIV. Together with other methods, they can create a virtuous circle: the amplification of ART for infected people would reduce the number of possible transmissions ${ }^{4}$, whereas the use of other methods would restrict the individuals more vulnerable to HIV in the population ${ }^{3}$.

Therefore, the combined offer of preventive methods on a large-scale, called combination prevention, associated with interventions in structural aspects ${ }^{5}$, is strongly recommended nowadays ${ }^{6}$. The United Nations ${ }^{2}$ proposes to countries coverage goals of effective testing and treatment of up to $90 \%$ until 2020 . With the "90/90/90 Strategy", in theory, the epidemic would be "over" until 2030.

The combination of preventive methods could also lead to important changes in the way individuals and social groups deal with risks and prevention, which would lead to 
more autonomy when facing the epidemic. Therefore, methods with different characteristics, which can be used at different times, tend to comprehend a larger number of people and situations. For instance, heterosexuals more often choose to use the condom in relationships with occasional partners ${ }^{7}$, and homosexuals often prefer non-penetrative sex and serological knowledge as an instrument of prevention ${ }^{8}$. Besides, a person can be submitted to multiple exposures to HIV in different circumstances, or its forms of exposure and protection can change throughout life. Also, the person may want to increase his or her level of protection in situations which could offer high exposure to the infection. In this sense, studies in Australia and in the United States of America (USA) showed that the use of post-exposure prophylaxis for consensual sexual activity (PEPsexual) by homosexuals is mostly addressed to suppressing flaws in other methods ${ }^{9}$. Likewise, the combination of the use of condoms and ART, according to a systematic review ${ }^{10}$, reduces the risk of infection in serodiscordant relationships in $99.2 \%$.

Another important aspect to be considered is that the characteristics of some methods increase the autonomy of individuals facing structural barriers. For prostitutes ${ }^{11}$ in violent situations, or who work without protection so as to obtain higher payment, the female condom can help to reduce risks, especially if associated with cash transfer strategies.

Finally, the access to preventive methods involves a connection with health services and communitarian institutions, allowing the users to benefit from other strategies of care. An example of that is that HIV testing is one of the most effective strategies to reduce incidence rates ${ }^{12}$, and is associated with the use of pre- and post-exposure prophylaxes and seroadaptative practices.

Facing this new reality and adopting the perspective of AIDS policies, the objective of this review was to examine preventive methods and structural interventions which, in the context of an epidemic that is concentrated in terms of population and geography, may have higher impact on incidence rates. We sought to analyze the knowledge regarding the level of protection provided by the different methods, their limits and potentials, as well as to discuss their combined and complementary offer.

\section{METHODOLOGICAL PROCEDURES}

We conducted a narrative literature review by selecting studies that analyzed the efficacy, the effectiveness or the impact of each preventive method against the HIV infection in unprotected sex and the incidence rates of HIV, prioritizing those that discussed facilitating elements and/or barriers to reach the maximum result of these methods. The main consulted base was the Scientific Library Online: U.S. National Library of Medicine (Pubmed), and we tried to select publications from 2012 on, in order to obtain studies that presented more recent findings, produced after the preconization of the combination prevention strategy.

However, we also analyzed some studies published in previous years, considered to be essential for presenting data from controlled clinical trials or efficacy studies. We complemented 
the analysis with references from some articles, and with the guidelines and technical recommendations of institutions in the field.

Considering the selection of studies conducted in contexts of concentrated epidemics, with a high burden of infection in homosexual relationships, we did not review male circumcision, which may be effective to prevent against HIV and sexually transmitted infections (STI), but has not been recommended as a public health strategy in these contexts. We did not include methods that are based on not having sexual intercourse, such as abstinence or postponement of sexual initiation.

We will present the results by separately analyzing the evidence of each method. Then, afterwards, we will stand out the role of structural interventions in the modification of social and programmatic contexts that interfere in HIV exposure.

\section{RESULTS}

\section{THE CLASSIC PREVENTIVE METHODS}

The traditional methods are the most famous ones, with easier access, acceptance and frequency of use, and also the ones presenting the fewer adverse effects. Some of them are the male and female condoms, non-penetrative sexual practices and use of the anti-HIV test as a way to guide sexual arrangements.

\section{The male condom}

The male condom was the first feasible response from public health for prevention, proving to be effective and cost-effective for HIV control ${ }^{13}$. Its level of protection against HIV sexual transmission is of $80 \%$ in heterosexual vaginal sex and $64 \%$ in anal homosexual sex, being also effective against some STIs: for both men and women, chlamydia, gonorrhea, herpes simplex type 2 and syphilis; and, only for women, trichomoniasis ${ }^{14}$. Among homosexuals, protection was of $42 \%$, considering urethral and rectal gonorrhea, chlamydia and syphilis ${ }^{15}$. There is no evidence of protection against HPV ${ }^{14}$; however, there is a vaccine for that. Protection against HIV was estimated for the use of condoms in all sexual intercourses (consistent use), without considering errors or problems with the product during penetration. In homosexual anal sex, using it only sometimes did not offer protection ${ }^{16}$.

The main factors related to reducing the effectiveness of the condom have been associated with incorrect use, inadequacy of the product to the user and quality issues ${ }^{17}$, and all of these have been widely reported ${ }^{18}$. Among them, some stand out, such as beginning penetration without the condom and putting it afterwards, or taking it off before the end (from 20 to $60 \%$ of the users); breaking and leaking (25-45\%); and inadequacy in terms 
of size and sensitivity, reported by approximately $45 \%$ of men, which has been associated with the increasing risk of breaking, slipping and losing pleasure ${ }^{17}$. Lubrication reduces the chances of breaking, especially in anal relations, but, on the other hand, it increases the risk of $\mathrm{STI}^{19}$ and lesion on the mucosa ${ }^{20}$.

The frequency of condom use in the first decades of the epidemic was marked by duality. On the one hand the use increased ${ }^{7,11,21}$, especially in relations with occasional partners, in those identified with risk of infection and in groups that were strongly affected by the epidemic. On the other, the consisted use for prolonged periods remained low, both among heterosexuals ${ }^{7}$ and homosexuals ${ }^{16}$, especially because of limited access, low risk perception, non-intention of use, desire for pleasure and use of alcohol and other drugs ${ }^{7,22-24}$.

However, solid evidence ${ }^{11,13,25-27}$ has shown that behavioral interventions were effective to promote the use of condoms and protected sex. Even though it is hard to restrict interventions to a specific number of successful initiatives, the ones presenting the best results in evaluative analyses were those in groups and communities (i.e., promoted the reduction of risk practices from 27 to $30 \%$ among homosexuals), as well as the ones that used motivational strategies of building skills and discussing preventive theories ${ }^{26,27}$. The association with structural interventions increased this effect ${ }^{11}$. And interventions with heterosexual couples reduced risk-associated practices ${ }^{28}$.

However, the limitation of these interventions ${ }^{29,30}$ lies on the difficult of conducting large-scale actions and on the diversity of the existing sexual behaviors and practices, as well as on the sustainability of changes in different circumstances of life. However, after a prolonged period, studies ${ }^{31}$ showed that differences between people who participated and those who did not participate in the interventions tended to become similar.

Then, more extensive and lasting behavioral changes could be especially a reflex of broader public health actions, which supported by clear and objective messages, and also by structural changes, engaged society in a movement towards facing the epidemic, triggering processes of social transformation ${ }^{29}$. Successful countries in terms of epidemic control, such as Thailand and Brazil, are examples of that, since their policies combined initiatives of social mobilization, individual behavioral changes, especially conducted by non-profit organizations, and structural interventions ${ }^{13,32}$.

\section{The female condom}

The female condom is marked by a binomial: whereas it is recognized as the most specific and adequate to the female body, besides being more associated with the construction of autonomy facing the epidemic ${ }^{33}$, it is also the method that has the lowest visibility in the scope of AIDS policies, since there are limitations regarding its increasing offer in the services ${ }^{34-36}$. Even though there is higher comparative scarcity 
in relation to other methods, studies have shown that the female condom is associated with the increasing number of safe practices ${ }^{37}$, and is effective to reduce the risk of STDs at least similarly to the male condom ${ }^{36}$. As an example, a study conducted with prostitutes in Thailand ${ }^{38}$ observed that houses that provided the female condom for clients who did not want to or could not use the male condom increased the protected practices and reduced the STI incidence rates in 24\% when compared to houses that only had the male condom (statistically not significant: 2.81 and 3.69 per 100 women-week, $\mathrm{p}=0.18)$. Estimates ${ }^{39}$ also indicate that if for every 10 relations with the male condom there was one with the female condom, more than 600 new infections could be prevented in Brazil, so it would be a cost-effective strategy. This scenario of cost-effectiveness is also observed in South Africa ${ }^{39}$. In this sense, a systematic review about interventions based on gender found that the distribution of female condoms for prostitutes is among the ten most cost-effective interventions conducted in this context $t^{40}$. Concerning safety, studies have shown rates of functional flaws between 2.5 and $25.1 \%$, especially because of the form of use. Studies that analyzed the presence of sperm in the vagina after sexual intercourse did not show statistical significance regarding the differential chances of acquisition and transmission of HIV for the female and male products ${ }^{39}$. The failure rates were similar for the three types of female condoms analyzed ${ }^{41}$.

There is controversy about the reasons restricting the increasing offer of female condoms, which remain reduced, about $1 \%$ in the population or in places with non-stimulated demand ${ }^{36}$. For some experts, the low demand is related to the lack of promotion policies ${ }^{36}$ or policies that create institutional barriers to the method ${ }^{33,35,42}$. Many of the arguments supporting these limitations result from studies of method acceptance conducted with women who never used the product or used it only a few times ${ }^{33,42}$. In these studies, the negative aspects for non-acceptance are associated, among others, to the "ugly" aspect of the product, size, apparently disproportional to the dimensions of the vagina, and difficulties of insertion. Other obstacles are the high price and the lower availability in services and in the private market ${ }^{37}$. In effect, the more frequent use has been subsidized by projects of intervention ${ }^{36}$.

On the other hand, there is agreement regarding the need to provide counseling and training to promote higher acceptance and use of this product. In these conditions, studies observed high acquiescence, of about 50\%, and it can be higher among women who are more vulnerable to the infection, like prostitutes ${ }^{42}$. According to the tendency observed with other contraceptive methods, this acceptance tends to increase with the experience of use, and can range according to social groups and cultures $\mathrm{s}^{35,37}$.

Some of the most important aspects are power and autonomy for the preventive practice in restricted situations of negotiation with the partner, as well as the preference regarding hormonal contraceptive methods ${ }^{33,36,42}$. Still, studies show there are only a few reports of non-acceptance by the partner, and that its use can help to reduce gender inequalities, mostly observed in more exposed groups $s^{33,40,43}$. 


\section{Non-penetrative practices and anti-HIV test to choose partners and sexual practice}

Sexual relations without condoms have been practiced with the adoption of other preventive methods, especially non-penetrative relations and the use of anti-HIV test to select partners or choose the type of sexual practice: the set of preventive practices based on serological status has been called seroadaptive practices ${ }^{8}$. These methods, which are based on the logic of risk reduction in sexual relations, appeared as a communitarian response, and often were superposed to regulatory public health strategies, with higher impact on sexual practices. Therefore, in some contexts, the use of "communitarian methods" has been more common, with more adherence than others ${ }^{44,45}$.

Non-penetrative relations are supposedly totally effective in terms of prevention; and the use of the anti-HIV test by a seronegative person, aiming to limit penetration without condoms among people with the same serological status (serosorting), has a 53\% level of protection against HIV and $14 \%$ against STIs in homosexual relations ${ }^{46}$. This level of protection was estimated in the comparison with the use of no protection at all during the sexual intercourse. The anti-HIV test as an instrument of prevention, however, increased the risk of HIV and STI in 79 and 61\%, respectively, when compared to the consistent use of the condom.

The reduced effectiveness of serosorting is owed to a series of limitations of the method itself $^{46-48}$, many of which are related to the reliability of information about the partner and to the context of the sexual relation. Some situations may reduce the level of protection: those implicating embarrassment for the revelation of the diagnosis, such as stigma or criminalization of HIV transmission; the ones with restricted testing offer; high prevalence of HIV and late diagnosis; and low ART coverage. It is important to consider incidence rates with growing tendency, which will increase the chances of sexual relations with recently infected people and those in phase of acute infection. It is important to emphasize that studies about the effectiveness of serosorting were conducted in high income countries, where these issues have lower impact. In stable relationships, protection also depends on the fulfillment of other agreements, such as fidelity or use of protection with casual partners.

Other seroadaptive practices ${ }^{44,45}$ for seronegative people involve the knowledge about the result of the partner's test to use the condom only with those whose serostatus is unknown or positive ("condom serosorting"); with infected partners, define the sexual practice according to ART and the viral load, or choose for the insertive practice, once it involves lower risks in relation to the receptive practice (strategic position or seroposition) ${ }^{10}$. It can also include the interruption of penetration before ejaculation.

In Brazil, the frequency of use of the test for prevention is relatively unknown, but qualitative studies suggest that it is lower than that in the USA and Europe ${ }^{49}$. In high income countries, seroadaptive practices are used by three out of four homosexuals ${ }^{12,44,50}$. The most common practices are: asking the serological status, serosorting and interrupting penetration. These practices are not restricted to homosexuals, since similar situations among heterosexuals are described ${ }^{51}$. 


\section{THE BET TO END THE EPIDEMIC: TREATMENT AS PREVENTION}

Treatment as prevention (TasP) has been often pointed out as the most effective technology for the mid-term control of the epidemic ${ }^{2}$ as the suppression of viral replication reduces HIV transmissibility in $96 \% \%^{52}$. Observational and mathematical studies have shown the impact of TasP on HIV incidence. The analysis of a cohort of 17 non-infected people, observed for 7 years in South Africa, showed that for every $1 \%$ of increasing rates of ART coverage there was a $1.4 \%$ decline in the risk of infection for the population ${ }^{53}$. In this sense, modelling studies ${ }^{54}$ estimated that, in 8 years, an ART program with $80 \%$ coverage and $85 \%$ retention in clinical follow-up would reduce incidence rates from 35 to $45 \%$. TasP was also pointed out as having the highest impact and best cost-effectiveness in terms of infections prevented and more years of life ${ }^{55}$.

This evidence motivated the United Nations Program about HIV/AIDS (UNAIDS) to state that the elimination of the epidemic would be possible until 2030, as long as countries could make sure that $90 \%$ of the infected people are diagnosed, and $81 \%$ of them do not have, until 2020, the virus detected in the plasma ${ }^{2}$. In this context, Brazil changed its clinical protocols so that the beginning of ART can be provided to all infected individuals immediately after diagnosis.

The perspective for the end of the epidemic based on the expansion of TasP, however, has been strongly criticized. Many mathematicians ${ }^{54}$, when using different techniques and parameters, do not agree with the estimates and with the possibility that the TasP can lead the incidence to reduce to levels lower than $0.1 \%$ in the mid and long terms. To reinforce that criticism, studies that analyze the tendency of the epidemic in countries with good health structure, which reached high levels of testing and ART coverage according to clinical protocols throughout time, like France, Australia and the USA ${ }^{56}$, observed that despite the reduction, incidence rates remained high or started growing again after the ART. The limit of the population effects of the TasP is related to aspects that are extrinsic and intrinsic to the method. One of them refers to a combination between the increasing number of unprotected practices in the population, regardless of the introduction of new preventive methods, which has been reported in different contexts ${ }^{56}$, and the existence of groups of infected people who are unaware of their serological status, or have a detectable viral load ${ }^{57}$, contributing with the maintenance of high rates of HIV incidence. This can happen even where the proportion of seropositive people, who are aware of their status, is high. In the USA, for example, $49 \%$ of the new infections were attributed to the $20 \%$ of people who did not know about the positive test ${ }^{58}$.

Besides, in the $\mathrm{USA}^{59}$, rates of treatment retention remain low, not overcoming $55 \%$. In Brazil, it is estimated that the number of people who know their positive status and are not being followed-up or need recent information about the viral load is about twice as high as that of infected people without a diagnosis ${ }^{1}$. In spite of that, estimates warn for the fact that, even improving the continuum of care of infected people, from diagnosis to viral suppression, the impact on incidence would be of $16 \%$ in a concentrated epidemic. The more 
effective actions would be the adherence to ART and the increasing frequency and coverage of tests ${ }^{60}$.

However, even assuming the high quality of care, it is important to consider that infected people may use the right not to initiate TasP, which has been frequent ${ }^{61}$. For many infected people, diagnosis leads to reduced sexual activity and increasing safe practices, encouraged by the fear of transmitting the virus, stigma, loss of pleasure or difficulty to reveal diagnosis. Because of that, there is a sense of comfort in the preventive methods that are already used, dismissing the need for additional protection ${ }^{62}$. Besides, studies show that some patients wish to postpone the beginning of ART for fear of adverse effects and treatment costs. Some patients are unaware of the TasP benefits, and they do not believe that it can no longer transmit the virus, fearing its consequences, like STIs, resistant virus or criminalization ${ }^{63}$. Similar doubts about TasP are observed among health providers ${ }^{64}$.

\section{PREVENTION FOR PEOPLE WHO ARE MORE EXPOSED AND DO NOT WANT TO OR CANNOT USE A CONDOM: PRE-EXPOSURE PROPHYLAXIS FOR THE PREVENTION OF SEXUAL HIV TRANSMISSION}

Pre-exposure prophylaxis (PrEP), which consists of the daily oral use of ART by non-infected people, is the newest among preventive methods, and is also controversial. There are not many doubts about the fact that the use of ART can offer high level of protection in the sexual transmission of HIV. In an open study, conducted with homosexuals and transgender people coming from randomized clinical trials, the use of a daily oral dose of tenofovir disoproxil fumarate plus emtricitabine (TDF/FTC) from 4 to 7 days of the week was not associated with any occurrence of infection in a 72-week period ${ }^{65}$. Adherence to PrEP to obtain this level of protection was observed in one third of the total number of visits when blood levels of the drug were measured. The global rate of infection among those who used PrEP was 1.8 per 100 people-year, which means a $49 \%$ protection in relation to those who did not use PrEP after the clinical trials.

Showing difficulties in adherence, two efficacy studies ${ }^{6,67}$ previously conducted with African women who are more exposed to HIV did not identify a level of protection for the group that used PrEP. In one of them, FEM-PrEP, great levels of drug concentration in the blood were observed for $12 \%$ of the women, when considering the whole study period ${ }^{68}$. Other factors may also have contributed with the lack of success, such as the lower concentration of the drug in the vaginal tissue, in comparison to the anal tissue, absence of solution of continuity in the epithelial tissue, caused by infections and inflammations, or different exposures with partners in the acute phase of the HIV infection ${ }^{69}$.

A meta-analysis ${ }^{70}$ assessing the 4 clinical trials that compared the use of TDF/FTC with placebo reached a synthesized measure of $51 \%$ of the level of protection of PrEP 
(95\%CI $0.15-0.72)$, analyzing 8,918 men and women being heterosexual, homosexual, transgender and serodiscordant couples, all with higher risk for HIV. Two recent studies, however, showed significantly higher effectiveness of PrEP. One of them ${ }^{71}$, involving French and Canadian homosexuals in a controlled clinial trial, investigated the use of PrEP only on the days prior to unprotected sex and in the 24 and 48 hours after, called PrEP on demand. The risk reduction in the group that used PrEP was 86\% (95\%CI $39.4-$ 98.5). This same reduction in the risk of infection (86\%; 90\%CI 62-96) was observed in an open study ${ }^{72}$ with British homosexuals, when compared to the group that did not start PrEP immediately. This result allows formulating the hypothesis that the use of PrEP in the everyday life may have higher adherence than in clinical trials, once individuals who choose to use prophylaxis in real life have additional motivations for the consistent use of the drug.

Many questions exist in this scenario ${ }^{73,74}$ regarding the large-scale offer of a preventive method with divergences that are not yet completely solved in terms of effectiveness, adherence rates, and about how, in the long term, possible relapse effects will behave in the preventive practice and the selection of resistant viruses. That is why it has been recommended that the offer of PrEP can come first in demonstrative projects, able to explore its function in daily situations.

A previous analysis of this experimental phase was observed in a post-clinical trial open study ${ }^{65}$ in which the acceptance of continuation of PrEP use by the participants of previous phases was high $(\sim 65 \%)$. The highest rates of adherence to prophylaxis were observed among those with higher schooling, age and riskier practices; according to a pattern that intercalated the more intensive use and discontinuity; and with many infections occurring in the periods of non-use. Interruptions were mainly motivated by the choice of the user, adverse effects and occurrence of non-related comorbidities, and have not been associated with the use of alcohol and other substances. Sexual practices associated to higher risks decreased with time.

This scenario corroborates the point of view ${ }^{75}$ that PrEP is offered as an additional preventive method for people with higher risk of infection, for having unprotected penetrative sex. In this context, a systematic review ${ }^{76}$ of the studies that estimated the impact and cost of PrEP on the epidemic showed that the offer of prophylaxis may have a significant impact on the reduction of incidence and be cost-effective, especially if people with higher risk were to be prioritized. In concentrated epidemics ${ }^{77,78}$, even in a scenario of amplification of TasP and moderate changes in sexual practices, the impact of PrEP would be significant, even though the authors warn us that the sensitivity analyses indicated that an unlikely increase in large-scale risk practices would lead to increasing incidence $^{78}$. In these studies, the higher PrEP limiting factor was the high cost in the current values of the reference product.

From the population point of view, considering the social groups that are mostly exposed to HIV, the intention to use PrEP, apparently, is low due to concerns about effectiveness, use of ART and their adverse events and low risk perception ${ }^{79,80}$. Therefore, the high acceptance 
in open studies could be attributed to the previous selection of people with higher exposure to $\mathrm{HIV}^{65}$. Even between serodiscordant partners, the preference tends to be addressed to the use of ART by the infected partner ${ }^{81}$.

\section{THE LAST OPTION OF PREVENTION FOR NON-INFECTED PEOPLE: POST-EXPOSURE PROPHYLAXIS}

Post-exposure prophylaxis for consensual sexual activity (PEPsexual) is the oldest of "biomedical methods" and consists of a window of opportunity of up to 72 hours after exposure to HIV, in which the effective use of ART, for 28 days, inhibits the effectiveness of the infection. Even though there are no efficacy studies, for ethical reasons, a body of evidence about the level of PEPsexual protection has been built with time, based on the analogous use of prophylaxis in animal models ${ }^{82}$, perinatal clinical studies and those of vertical transmission ${ }^{83}$ and in observational studies with health professionals who have been exposed due to their occupation ${ }^{84}$. Recently, a meta-analysis ${ }^{85}$ of studies that assessed the use of PEP in animal models reached a synthetized protection measurement of $89 \%$ in risk reduction among non-humans who received PEP.

The use of PEPsexual is indicated when the risk of infection in the exposure is relevant, so each case should be assessed individually ${ }^{86}$, with special attention to unprotected penetrative sex with an infected partner, or, in the case of unknown serological status for HIV, the fact of belonging to groups with higher prevalence. Recently, recommendations excluded the indication of PEPsexual in serodiscordant relations and undetectable viral load, except for receptive anal relations ${ }^{87}$.

PEPsexual plays a strategic role for being the last resource to prevent the acquisition of HIV, after the other methods have failed, or have not been used. In effect, PEPsexual as an emergency method has been used more as a complement than as a replacement for other preventive methods ${ }^{9}$. Approximately $80 \%$ of the users reported using PEPsexual a single time ${ }^{88}$.

Despite being strategic and having a long time of existence, the knowledge about PEPsexual is low among potential users and health professionals. In a study from the USA, $59.7 \%$ of the pathologists reported knowing PEPsexual, but $39.3 \%$ had never prescribed this method ${ }^{86}$. Likewise, in Spain, among people who looked for the anti-HIV test, $22 \%$ of them knew PEPsexual, and $2 \%$ had used this technique ${ }^{89}$. The use of the method was also low (34\%) among homosexuals who received ART to start prophylaxis in case of an unprotected relation ${ }^{90}$. Some of the reasons for low use are individual characteristics (i.e., perception of no risk and fear of adverse events); health services (i.e., few places that offer the medicine and time of service); and the method itself (i.e., 72-hour limit for the beginning of prophylaxis). In Brazil, the Ministry of Health registers the increasing use of PEPsexual (about 8 thousand prophylaxes in 2014), but it still remains two to three times lower than the use of occupational PEP. 
The impact of PEP on the epidemic is not clear yet. A few observational or modeling studies were conducted in this sense. An evaluation showed that, after six years, a PEP program in Australia prevented from one to nine cases of infection in the period ${ }^{91}$. The low impact was attributed to the reduced group of individuals who in fact had relations with an infected partner.

The reduced effectiveness of PEP has been associated with the high rates of non-adherence. In a meta-analysis ${ }^{92}$ that assessed data referring to approximately 3.6 thousand patients included in 17 studies, adherence rates ranged from 49 to $92 \%$, with a synthesized measure of $69 \%(95 \%$ CI $59-72)$, considering a 28 -day follow-up. The main reason for non-adherence was the adverse effects, but in some cases users believed the risk of exposure was low, or that the number of days on ART were sufficient, besides the loss of interest in continuing the treatment. In places where prophylaxis was initiated in emergency services, loss can be higher, like in Boston (USA), where a little more than half of the people referred to treatment arrived at the reference service, and $23.6 \%$ completed the 28-day treatment ${ }^{93}$.

The effect of interventions to increase adherence is controversial. In a noninferiority trial, conducted with 457 PEP users in California (USA), counselling sessions to promote adherence did not result in higher rates of treatment ${ }^{94}$. The same result was observed in studies analyzed in a meta-analysis ${ }^{92}$, in which the adherence percentages did not range between locations with and without activities for adherence. The loss of effectiveness of PEPsexual can also be associated with the time of therapy onset and to the transmission of resistant viruses.

\section{NOT ALL METHODS SHOULD BE USED IN SEXUAL RELATIONS: STRUCTURAL INTERVENTIONS}

Structural interventions, understood as those that try to change the life conditions related to risk and vulnerability to $\mathrm{HIV}^{5}$, have gained relevance in terms of facing the epidemic 5,95 , both because they directly affect the causal chain of the epidemic, in the case of policies of criminalization of homophobia ${ }^{96}$, and because they reduce the limits to the access to services and use of preventive methods, as do the social programs addressed to ART adherence ${ }^{97}$. Therefore, more and more evidence shows that structural interventions increase the success of the response to the epidemic and the individual and community-based interventions ${ }^{5,95,98}$. A modeling study about the structural determinants of the HIV epidemic among prostitutes in several countries showed that the decriminalization of sexual work would prevent from 33 to $46 \%$ new infections throughout a decade, which is higher to that found for the impact of the amplification of ART ${ }^{96}$. Another systematic review showed that harm reduction programs for drug users carried out in a structural scope (i.e., more access to syringes in drugstores and elimination of prohibitions 
of drug paraphernalia) are able to reduce the incidence of HIV and hepatitis $\mathrm{C}$ in the general population ${ }^{99}$.

Even though structural interventions approach many actions and mobilize several fields of work, their most important impact comes from complementarity and synergy between the different types of intervention and involved parties, such as combined actions to change the macro and microstructural context, the delivery of services and health products and the mobilization of community ${ }^{100}$. This synergy between actions was the base of the program called " $100 \%$ Condom Use" 101 , conducted in the Asian southeast region, which involved, among others, the health and security sectors, commercial sex houses and prostitutes. The objective was to put the lemma "no condom, no sex" to use. Throughout a decade, it substantially change behaviors and the frequency of STIs and HIV.

Another aspect that guarantees a higher impact of structural interventions concerns the focus of work on social, political and economic features that are directly related to the causal chain of HIV. For instance, even though poverty plays a determinant role in terms of health, in HIV epidemics absolute poverty may have lower weight than other socioeconomic aspects. This is the case of Brazil, which registers more and more cases of people with lower income and an epidemic of low magnitude in cities with worse social indicators. Therefore, for the HIV epidemic, interventions to change social inequalities that are typical of urban centers, such as policies for the support and integration of migrants, promotion of equal access to services, specifically addressed to groups of higher risk, may have a higher impact on the reduction of HIV incidence rates than macro-structural policies, which are important but do not immediately affect the causal chain of the epidemic.

A path to improve the focus and the design of structural interventions involves community participation and mobilization. The groups that are mostly affected by the epidemic have more accurate perceptions about their needs and limits related to access to health. In effect, a systematic review ${ }^{102}$ that analyzed the impact of community mobilization identified consistent evidence that these interventions led to increasing preventive practices and reduced incidence of STIs, especially among prostitutes. Still, the felling of community belonging seems to have contributed for the behavioral change among homosexuals and prostitutes ${ }^{102}$. Another positive aspect of community participation is that it allows predicting possible social reactions facing proposals of context change and introduction of new prevention strategies. It is important to mention that the methods based on the use of ART were assessed in contexts of controlled studies and their transposition to real life can create resistance in the individual and collective scopes due to the little knowledge or the conflict with individual rights of not being tested or treated.

Besides, it is important to consider the difficulties to register the effects of structural interventions considering the changes in the course of the epidemic. For example, a randomized trial ${ }^{103}$ conducted to analyze combined micro-financing actions to 
generate income and intervention on gender and HIV aiming at reducing the violence against women and the incidence of HIV in South Africa succeeded by showing economic improvements and a $55 \%$ reduction on the violence practiced by intimate partners. However, it was unable to show the effects of intervention on sexual practices and on the incidence of HIV. Part of the difficulty ${ }^{102,104}$ is related to the limitation of the indicators that are usually adopted, whereas it is necessary to understand the reflection of structural changes in the course of the epidemic and the difficulties to distinguish the effects of macro-structural changes and other interventions in the context of daily practices.

\section{DISCUSSION}

We tried to show that, facing the specificities and limitations of each method, there is no "silver bullet" that is able to end the HIV epidemic. Simplistic policies to hierarchize the offer of methods based on efficacy criteria will always cast away a group of people, which can lead to the expansion of the epidemic in social groups and geographic regions. The best method (or methods) will be the one that is adequate to the situation and the context of each individual and their sexual relations throughout life, especially if these are chosen based on information and autonomy. Therefore, programs that offer combined methods will have higher changes of producing a stronger effect on the reduction of HIV incidence rates $^{6,55}$, including structural actions and methods that apparently have lower impact on the epidemic, like PEP.

Despite all the questions, most evidence shows that methods based on ART can fill the preventive gaps that exist up until now ${ }^{9,30,81}$; and that some of the population will choose to use it for several reasons ${ }^{49,65}$. However, the use of ART for prevention is new, and, as such, it is going through a process of innovation, both from the technological point of view ${ }^{105}$ and in practice ${ }^{73}$. Regarding PrEP, promising studies assess the reduction of excessive use of medication and facilitators to adherence ${ }^{105}$, such as drug dispensers for long periods, gel use or by demand, before and after relations, as well as the use of other drugs, such as maraviroc.

In the case of TasP, the experience of high-income countries tells us to be careful. In such contexts, the coverage of testing and treatment was not followed by the reduction of the epidemic ${ }^{56}$. Such situation is similar in Brazil, where high values of incidence and mortality rates coexist with rates of more than $75 \%$ people who are aware of their positive status and universal access to ART ${ }^{1}$. So, even though the higher effect of TasP on the epidemic is related to the improvement of care continuum ${ }^{60}$, especially adherence to treatment, other strategies for non-infected ${ }^{6}$ people are crucial.

The classic methods remain strategic, not only for their acceptance and level of knowledge $^{17,50}$, but also because they depend less on the structure of services and are rooted in the community, reflecting initiatives adopted to face the epidemic throughout these 
30 years $^{7,32,36}$. The seroadaptive practice, however, has not been part of the health policies due to a supposed absence or lack of effectiveness. The distance between public health and community response has not brought promising results ${ }^{5,6,29}$; and prevention policies will benefit from a more pragmatic view, recognizing that this method is better than the absence of any other ${ }^{46}$, that it has been widely used ${ }^{44}$ - and tends to increase with the self-test - and that it can be a viable alternative of prevention facing the restriction of other methods. However, it is important to mention that studies analyzing the extension and effectiveness of this method in middle income countries are necessary, both in homosexual and in heterosexual relations.

Some of the most relevant problems affect all methods equally, such as limits of access, lack of adherence and misuse. Behavioral interventions succeed in minimizing these problems, however, extensive and lasting changes are related to structural interventions and social mobilization ${ }^{5,29}$. In marginalized groups such as sex workers ${ }^{11}$, this dimension is crucial as behavioral initiatives will be insufficient in the absence of structural changes.

\section{CONCLUSION}

From the individual perspective, the availability of several preventive methods favors the protection in different moments of the chain of HIV transmission, and its complementary use promises consistent progress in the response to the epidemic with impact on the reduction of incidence. However, the new technological devices of the biomedical field do not survive outside of the social equipment, neither can they be isolated from the social contexts where they are provided. So, from the programmatic perspective, as widely recognized by several sectors, efforts should be made to improve the access to such methods, including the most traditional ones, such as male and female condoms, and, in a larger scale, to amplify others, like PEPsexual in the service network, TasP and PREP, whereas the evidence that is being produced about that in Brazil can subsidize the implementation of public policies in this field. Knowledge, access and adequate use of these methods in a large scale are essential for the effective control of the epidemic. Likewise, they depend on public health initiatives that can combine social participation, community mobilization, focus on the most affected groups and regions, structural and behavioral interventions, and professional education, besides qualified services addressed to the change in prevention models that the world is currently going through. This set of actions, which are articulated and combined in the different levels of care and in the wider scope of social life, can fight structural barriers and contribute to reduce the persistent stigma related to sexual choices, thus fulfilling the right of individuals to access prevention methods and strategies that are more adequate to their context of life. 


\section{REFERENCES}

1. Brasil. Ministério da Saúde. Secretaria de Vigilância em Saúde. Departamento Nacional de DST AIDS e Hepatites Virais. Boletim epidemiológico - AIDS e DST. Vol 1. Ano III. Brasília: Ministério da Saúde; 2014.

2. Joint United Nations Programme on HIV/AIDS. 90-90-90: an ambitious treatment target to help end the AIDS epidemic. Geneve: Joint United Nations Programme on HIV/AIDS; 2014. p. 33.

3. Chang LW, Serwadda D, Quinn TC, Wawer MJ, Gray RH, Reynolds SJ. Combination implementation for HIV prevention: moving from clinical trial evidence to population-level effects. Lancet Infect Dis 2013; 13(1): 65-76.

4. Investigating the impact of treatment on new HIV infections. PLoS Medicine 2012; 9: 92.

5. Gupta GR, Parkhurst JO, Ogden JA, Aggleton P, Mahal A. Structural approaches to HIV prevention. Lancet 2008; 372(9640): 764-75.

6. Jones A, Cremin I, Abdullah F, Idoko J, Cherutich P, Kilonzo N, et al. Transformation of HIV from pandemic to low-endemic levels: a public health approach to combination prevention. Lancet 2014; 384(9939): 272-9.

7. Hearst N, Chen S. Condom promotion for AIDS prevention in the developing world: is it working? Stud Fam Plann 2004; 35(1): 39-47.

8. McConnell JJ, Bragg L, Shiboski S, Grant RM. Sexual seroadaptation: lessons for prevention and sex research from a cohort of HIV-positive men who have sex with men. PLoS One 2010; 5(1): e8831.

9. Korner H, Hendry O, Kippax S. Safe sex after postexposure prophylaxis for HIV: intentions, challenges and ambivalences in narratives of gay men. AIDS Care 2006; 18(8): 879-87.

10. Patel P, Borkowf CB, Brooks JT, Lasry A, Lansky A, Mermin J. Estimating per-act HIV transmission risk: a systematic review. AIDS 2014; 28(10): 1509-19.

11. Bekker LG, Johnson L, Cowan F, Overs C, Besada D, Hillier S, et al. Combination HIV prevention for female sex workers: what is the evidence? Lancet 2015; 385(9962): 72-87.

12. Fonner VA, Denison J, Kennedy CE, O’Reilly K, Sweat M. Voluntary counseling and testing (VCT) for changing HIV-related risk behavior in developing countries. Cochrane Database Syst Rev 2012; 9: CD001224-CD001224.

13. Pattanaphesaj J, Teerawattananon Y. Reviewing the evidence on effectiveness and cost-effectiveness of HIV prevention strategies in Thailand. BMC Public Health 2010; 10: 401.
14. Holmes KK, Levine R, Weaver M. Effectiveness of condoms in preventing sexually transmitted infections. Bull World Health Organ 2004; 82(6): 454-61.

15. World Health Organization. Guidelines: prevention and treatment of HIV and other sexually transmitted infections among men who have sex with men and transgender people: recommendations for a public health approach. Geneve: World Health Organization; 2011.

16. Smith DK, Herbst JH, Zhang X, Rose CE. Condom effectiveness for HIV prevention by consistency of use among men who have sex with men in the United States. J Acquir Immune Defic Syndr 2015; 68(3): 337-44.

17. Crosby R. State of condom use in HIV prevention science and practice. Current HIV/AIDS Reports 2013; 10(1): 59-64.

18. Sanders SA, Yarber WL, Kaufman EL, Crosby RA, Graham CA, Milhausen RR. Condom use errors and problems: a global view. Sexual Health 2012; 9(1): 81-95.

19. Gorbach PM, Weiss RE, Fuchs E, Jeffries RA, Hezerah M, Brown S, et al. The slippery slope: lubricant use and rectal sexually transmitted infections: a newly identified risk. Sex Transm Dis 2012; 39(1): 59-64.

20. Dezzutti CS, Brown ER, Moncla B, Russo J, Cost M, Wang L, et al. Is wetter better? An evaluation of overthe-counter personal lubricants for safety and antiHIV-1 activity. PLoS One 2012; 7(11): e48328.

21. Berhan Y, Berhan A. Meta-analysis on risky sexual behaviour of men: Consistent findings from different parts of the world. AIDS Care 2012; 25(2): 151-9.

22. Rizkalla C, Bauman LJ, Avner JR. Structural impediments to condom access in a high $\mathrm{HIV} /$ stirisk area. J Environ Public Health 2010; 2010: 630762.

23. Suarez T, Miller J. Negotiating risks in context: a perspective on unprotected anal intercourse and barebacking among men who have sex with menwhere do we go from here? Arch Sex Behav 2001; 30(3): 287-300.

24. Blais M. Vulnerability to HIV among regular male partners and the social coding of intimacy in modern societies. Cult Health Sex 2006; 8(1): 31-44.

25. Herbst JH, Beeker C, Mathew A, McNally T, Passin WF, Kay LS, Crepaz N, Lyles CM, Briss P, Chattopadhyay S, Johnson RL; Task Force on Community Preventive Services. The effectiveness of individual-, group-, and community-level HIV behavioral risk-reduction interventions for adult men who have sex with men: a systematic review. Am J Prev Med 2007; 32(4 Suppl): 38-67. 
26. Lorimer K, Kidd L, Lawrence M, McPherson K, Cayless S, Cornish F. Systematic review of reviews of behavioural HIV prevention interventions among men who have sex with men. AIDS Care 2013; 25(2): 133-50.

27. Tan JY, Huedo-Medina TB, Warren MR, Carey MP, Johnson BT. A meta-analysis of the efficacy of HIV/ AIDS prevention interventions in Asia, 1995-2009. Soc Sci Med 2012; 75(4): 676-87.

28. LaCroix JM, Pellowski JA, Lennon CA, Johnson BT. Behavioural interventions to reduce sexual risk for HIV in heterosexual couples: a meta-analysis. Sex Transm Infect 2013; 89(8): 620-27.

29. Coates TJ, Richter L, Caceres C. Behavioural strategies to reduce HIV transmission: how to make them work better. Lancet 2008; 372(9639): 669-84.

30. Sullivan PS, Carballo-Diéguez A, Coates T, Goodreau SM, McGowan I, Sanders EJ, et al. Successes and challenges of HIV prevention in men who have sex with men. Lancet 2012; 380(9839): 388-99.

31. Feldman M, Silapaswan A, Schaefer N, Schermele D. Is there life after debi? Examining health behavior maintenance in the diffusion of effective behavioral interventions initiative. Am J Community Psychol 2014; 53(3-4): 286-313

32. Berkman A, Garcia J, Muñoz-Laboy M, Paiva V, Parker R. A critical analysis of the brazilian response to HIV/ AIDS: lessons learned for controlling and mitigating the epidemic in developing countries. Am J Public Health 2005; 95(7): 1162-72.

33. Gollub EL. The female condom: tool for women's empowerment. Am J Public Health 2000; 90(9): 1377-81.

34. Ventura-DiPersia C, Rodriguez K, Kelvin EA. Failure of many United States Department of Health Web sites to provide accurate information about the female condom. Contraception 2015; 92(1): 40-5.

35. Peters A, Jansen W, van Driel F. The female condom: the international denial of a strong potential. Reprod Health Matters 2010; 18(35): 119-28.

36. Gallo MF, Kilbourne-Brook M, Coffey PS. A review of the effectiveness and acceptability of the female condom for dual protection. Sex Health 2012; 9(1): 18-26.

37. Vijayakumar G, Mabude Z, Smit J, Beksinska M, Lurie M. A review of female-condom effectiveness: patterns of use and impact on protected sex acts and STI incidence. Int J STD AIDS 2006; 17(10): 652-9.

38. Fontanet AL, Saba J, Chandelying V, Sakondhavat C, Bhiraleus P, Rugpao S, et al. Protection against sexually transmitted diseases by granting sex workers in Thailand the choice of using the male or female condom: results from a randomized controlled trial. AIDS 1998; 12(14): 1851-9.
39. Dowdy DW, Sweat MD, Holtgrave DR. Country-wide distribution of the nitrile female condom (FC2) in Brazil and South Africa: a cost-effectiveness analysis. AIDS 2006; 20(16): 2091-8.

40. Remme M, Siapka M, Vassall A, Heise L, Jacobi J, Ahumada C, et al. The cost and cost-effectiveness of gender-responsive interventions for HIV: a systematic review. J Int AIDS Soc 2014; 17(1): 19228.

41. Beksinska ME, Piaggio G, Smit JA, Wu J, Zhang Y, Pienaar J, et al. Performance and safety of the secondgeneration female condom (FC2) versus the Woman's, the VA worn-of-women, and the Cupid female condoms: a randomised controlled non-inferiority crossover trial. Lancet Glob Health 2013; 1(3): e146-e152.

42. Peters A, Van Driel F, Jansen W. Acceptability of the female condom by Sub-Saharan African women: a literature review: original research article. Afr J Reprod Health 2014; 18(4): 34-44.

43. Weeks M, Zhan W, Li J, Hilario H, Abbott M, Medina $Z$. Female condom use and adoption among men and women in a general low-income urban u.s. population. AIDS Behav. 2015 [Epub ahead of print].

44. Dubois-Arber F, Jeannin A, Lociciro S, Balthasar H. Risk reduction practices in men who have sex with men in Switzerland: serosorting, strategic positioning, and withdrawal before ejaculation. Arch Sex Behav 2012; 41(5): 1263-72.

45. McFarland W, Chen Y-H, Raymond HF, Nguyen B, Colfax G, Mehrtens J, et al. HIV seroadaptation among individuals, within sexual dyads, and by sexual episodes, men who have sex with men, San Francisco, 2008. AIDS Care 2011; 23(3): 261-8.

46. Kennedy CE, Bernard LJ, Muessig KE, Konda KA, Akl EA, Lo YR, et al. Serosorting and HIV/STI infection among HIV-negative MSM and transgender people: a systematic review and meta-analysis to inform WHO guidelines. Sexually Transmitted Diseases 2013; 2013: 8.

47. Eaton LA, Kalichman SC, O’Connell DA, Karchner WD. A strategy for selecting sexual partners believed to pose little/no risks for HIV: serosorting and its implications for HIV transmission. AIDS Care 2009; 21(10): 1279-88.

48. O'Connell A, Reed S, Serovich J. The efficacy of serostatus disclosure for HIV transmission risk reduction. AIDS Behav 2015; 19(2): 283-90.

49. Lippman SA, Koester KA, Amico KR, Lama JR, Martinez Fernandes N, Gonzales P, et al. Client and provider perspectives on new HIV prevention tools for MSM in the Americas. PLoS One 2015; 10(3): e0121044.

50. Bogowicz P, Moore D, Kanters S, Michelow W, Robert W, Hogg R, et al. HIV testing behaviour and use of risk reduction strategies by HIV risk category among MSM in Vancouver. Int J STD AIDS 2015. [Epub ahead of print] 
51. Liu C, Hu H, Goparaju L, Bacchetti P, Weber K, Correa $\mathrm{N}$, et al. Sexual serosorting among women with or at risk of HIV infection. AIDS Behav 2011; 15(1): 9-15.

52. Cohen MS, Chen YQ, McCauley M, Gamble T, Hosseinipour MC, Kumarasamy N, et al. HPTN 052 Study Team. Prevention of HIV-1 infection with early antiretroviral therapy. N Engl J Med 2011; 365(6): 493-505.

53. Tanser F, Bärnighausen T, Grapsa E, Zaidi J, Newell M-L. High coverage of ART associated with decline in risk of HIV acquisition in rural kwazulu-natal, South Africa. Science 2013; 339(6122): 966-71.

54. Eaton JW, Johnson LF, Salomon JA, Bärnighausen T, BendavidE, Bershteyn A, et al. HIV treatment as prevention: systematic comparison of mathematical models of the potential impact of antiretroviral therapy on HIV incidence in South Africa. PLoS Med 2012; 9(7): e1001245.

55. Cremin I, Alsallaq R, Dybul M, Piot P, Garnett G, Hallett TB. The new role of antiretrovirals in combination HIV prevention: a mathematical modelling analysis. AIDS 2013: 27(3): 447-58.

56. Wilson DP. HIV treatment as prevention: natural experiments highlight limits of antiretroviral treatment as HIV prevention. PLoS Med 2012; 9(7): e1001231.

57. Hall HI, Holtgrave DR, Tang T, Rhodes P. HIV transmission in the United States: considerations of viral load, risk behavior, and health disparities. AIDS Behav 2013; 17(5): 1632-6.

58. Hall HI, Holtgrave DR, Maulsby C. HIV transmission rates from persons living with HIV who are aware and unaware of their infection. AIDS 2012; 26(7): 893-6.

59. Gardner EM, McLees MP, Steiner JF, Del Rio C, Burman WJ. The spectrum of engagement in HIV care and its relevance to test-and-treat strategies for prevention of HIV infection. Clin Infect Dis 2011; 52(6): 793-800.

60. Birger RB, Hallett TB, Sinha A, Grenfell BT, Hodder SL. Modeling the impact of interventions along the HIV continuum of care in Newark, New Jersey. Clin Infect Dis 2014: 58(2): 274-84.

61. Charurat ME, Emmanuel B, Akolo C, Keshinro B, Nowak RG, Kennedy S, et al. TRUST Study Group. Uptake of treatment as prevention for HIV and continuum of care among HIV-positive men who have sex with men in Nigeria. J Acquir Immune Defic Syndr 2015; 68(2 Suppl): S114-23.

62. Closson EF, Mimiaga MJ, Sherman SG, Tangmunkongvorakul A, Friedman RK, Limbada $\mathrm{M}$, et al. HPTN063 study team. Intimacy versus Isolation: a qualitative study of sexual practices among sexually active HIV-infected patients in HIV care in Brazil, Thailand, and Zambia. PLoS One 2015; 10(3): e0120957.
63. Young I, Flowers P, McDaid LM. Key factors in the acceptability of treatment as prevention (TasP) in Scotland: a qualitative study with communities affected by HIV. Sex Transm Infect 2015; 91(4): 269-74.

64. Evans C, Bennett J, Croston M, Brito-Ault N, Bruton J. "In reality, it is complex and difficult": UK nurses' perspectives on "treatment as prevention" within HIV care. AIDS Care 2015; 27(6): 753-7.

65. Grant RM, Anderson PL, McMahan V, Liu A, Amico KR, Mehrotra M, et al. Uptake of pre-exposure prophylaxis, sexual practices, and HIV incidence in men and transgender women who have sex with men: a cohort study. Lancet Infect Dis 2014; 14(9):820-9.

66. Van Damme L, Corneli A, Ahmed K, Agot K, Lombaard J, Kapiga S, et al. FEM-PrEP Study Group. Preexposure prophylaxis for HIV infection among african women. N Engl J Med 2012; 367(5): 411-22.

67. Marrazzo J, Ramjee G, Nair G, Palanee T, Mkhize B, Nakabiito C, et al. Pre-exposure prophylaxis for HIV in women: daily oral tenofovir, oral tenofovir/emtricitabine, or vaginal tenofovir gel in the VOICE study (MTN 003). Paper presented at: 20th Conference on Retroviruses and Opportunistic infections; 2013.

68. Corneli AL, Deese J, Wang M, Taylor D, Ahmed K, Agot K, et al. FEM-PrEP: adherence patterns and factors associated with adherence to a daily oral study product for pre-exposure prophylaxis. J Acquir Immune Defic Syndr 2014; 66(3): 324-31.

69. van der Straten A, Van Damme L, Haberer JE, Bangsberg DR. Unraveling the divergent results of pre-exposure prophylaxis trials for HIV prevention. AIDS 2012; 26(7): F13-9.

70. Okwundu CI, Uthman OA, Okoromah CA. Antiretroviral pre-exposure prophylaxis (PrEP) for preventing HIV in high-risk individuals. Cochrane Database of Systematic Reviews 2012; 7: CD007189.pub3.

71. Molina J, Capitant C, Spire B, Meyer L, Spire B, Pialoux $G$, et al. On demand PrEP with oral TDF-FTC in MSM: results of the ANRS Ipergay trial. Paper presented at: Conference on Retroviruses and Opportunistic Infections; 2015.

72. McCormack S, Dunn D. Pragmatic Open-Label Randomised Trial of Preexposure Prophylaxis: The PROUD Study. Paper presented at: Conference on Retroviruses and Opportunistic Infections; 2015.

73. Molina J-M, Pintado C, Gatey C, Ponscarme D, Charbonneau P, Loze B, et al. Challenges and opportunities for oral pre-exposure prophylaxis in the prevention of HIV infection: where are we in Europe? BMC Medicine 2013; 11: 186. 
74. Rennie S. Ethical use of antiretroviral resources for HIV prevention in resource poor settings. Dev World Bioeth 2013; 13(2): 79-86.

75. Centers for Disease Control and Prevention. Preexposure prophylaxis for the prevention of HIV infection in the united states - 2014: clinical practice guideline. Atlanta: Centers for Disease Control and Prevention; 2014. p. 67.

76. Gomez GB, Borquez A, Case KK, Wheelock A, Vassall A, Hankins C. The cost and impact of scaling up preexposure prophylaxis for HIV prevention: a systematic review of cost-effectiveness modelling studies. PLoS Med 2013; 10(3): e1001401.

77. Gomez GB, Borquez A, Caceres CF, Segura ER, Grant RM, Garnett GP, et al. The potential impact of pre-exposure prophylaxis for HIV prevention among men who have sex with men and transwomen in Lima, Peru: a mathematical modelling study. PLoS Med 2012; 9(10): e1001323.

78. Juusola JL, Brandeau ML, Owens DK, Bendavid E. The cost-effectiveness of preexposure prophylaxis for HIV prevention in men who have sex with men in the United States. Ann Intern Med 2012; 156(8): 541-50.

79. King H, Keller S, Giancola M, Rodriguez DA, Chau JJ, Young JA,et al. Pre-exposure prophylaxis accessibility research and evaluation (PrEPARE Study). AIDS Behav 2014; 18(9): 1722-5.

80. Holt M, Lea T, Murphy D, Ellard J, Rosengarten M, Kippax S, et al. Willingness to use HIV pre-exposure prophylaxis has declined among australian gay and bisexual men: results from repeated national surveys, 2011-2013. J Acquir Immune Defic Syndr 2014; 67(2): 222-6.

81. Fowler N, Arkell P, Abouyannis M, James C, Roberts L. Attitudes of serodiscordant couples towards antiretroviralbased HIV prevention strategies in Kenya: a qualitative study. J Int AIDS Soc 2014; 17(Suppl 3): 19563.

82. Black RJ. Animal studies of prophylaxis. Am J Med 1997; 102(5B): 39-44.

83. Sperling RS, Shapiro DE, Coombs RW, Todd JA, Herman SA, McSherry GD, et al. Maternal viral load, zidovudine treatment, and the risk of transmission of human immunodeficiency virus type 1 from mother to infant. N Engl J Med 1996; 335(22): 1621-9.

84. Cardo DM, Culver DH, Ciesielski CA, Srivastava PU, Marcus R, AbiteboulD, et al. A case-control study of HIV seroconversion in health care workers after percutaneous exposure. N Engl J Med 1997; 337(21): 1485-90.

85. Irvine C, Egan KJ, Shubber Z, Van Rompay KKA, Beanland RL, Ford N. Efficacy of HIV postexposure prophylaxis: systematic review and meta-analysis of nonhuman primate studies. Clin Infect Dis 2015; 60(Supplement 3): S165-9.
86. Rodríguez A, Castel AD, Parish CL, Willis S, Feaster DJ, Kharfen M, et al. HIV medical providers' perceptions of the use of antiretroviral therapy as non-occupational post- exposure prophylaxis (nPEP) in two major metropolitan areas. J Acquir Immune Defic Syndr 2013; 64 Suppl 1: S68-79.

87. Benn P, Fisher M, Kulasegaram R; BASHH; PEPSE Guidelines Writing Group Clinical Effectiveness Group. UK guideline for the use of post-exposure prophylaxis for HIV following sexual exposure (2011). Int J STD AIDS 2011; 22(12): 695-708.

88. Armishaw J, Hoy JF, Watson KM, Wright EJ, Price BG, Pierce AB. Non-occupational post-exposure prophylaxis in Victoria, Australia: responding to high rates of re-presentation and low rates of follow-up. Int J STD AIDS 2011; 22(12): 714-8.

89. Fernández-Balbuena S, Belza MJ, Castilla J, Hoyos J, Rosales-Statkus ME, Sánchez R, de la Fuente L; Madrid Rapid HIV Testing Group. Awareness and use of nonoccupational HIV post-exposure prophylaxis among people receiving rapid HIV testing in Spain. HIV Med 2013; 14(4): 252-7.

90. Schechter M, do Lago RF, Mendelsohn AB, Moreira RI, Moulton LH, Harrison LH; Praca Onze Study Team. Behavioral impact, acceptability, and HIV incidence among homosexual men with access to postexposure chemoprophylaxis for HIV. J Acquir Immune Defic Syndr 2004; 35(5): 519-25.

91. Poynten IM, Smith DE, Cooper DA, Kaldor JM, Grulich AE. The public health impact of widespread availability of nonoccupational postexposure prophylaxis against HIV. HIV Med 2007; 8(6): 374-81.

92. Oldenburg CE, Bärnighausen T, Harling G, Mimiaga MJ, Mayer $\mathrm{KH}$. Adherence to post-exposure prophylaxis for non-forcible sexual exposure to HIV: A systematic review and meta-analysis. AIDS Behav 2014; 18(2): 217-25.

93. Bogoch II, Scully EP, Zachary KC, Yawetz S, Mayer KH, Bell CM, et al. Patient attrition between the emergency department and clinic among individuals presenting for HIV nonoccupational postexposure prophylaxis. Clin Infect Dis 2014; 58(11): 1618-24.

94. Roland ME, Neilands TB, Krone MR, Coates TJ, Franses $\mathrm{K}$, Chesney MA, et al. A randomized noninferiority trial of standard versus enhanced risk reduction and adherence counseling for individuals receiving postexposure prophylaxis following sexual exposures to HIV. Clin Infect Dis 2011; 53(1): 76-83.

95. Seeley J, Watts CH, Kippax S, Russell S, Heise L, Whiteside A. Addressing the structural drivers of HIV: a luxury or necessity forprogrammes? J Int AIDS Soc 2012; 15(Suppl 1): 17397. 
96. Nordling L. Homophobia and HIV research: Under siege. Nature 2014; 509: 274-5.

97. Bärnighausen T, Chaiyachati K, Chimbindi N, Peoples A, Haberer J, Newell ML. Interventions to increase antiretroviral adherence in sub-Saharan Africa: a systematic review of evaluation studies. Lancet Infec Dis 2011; 11(12): 942-51.

98. Sumartojo E. Structural factors in HIV prevention: concepts, examples, and implications for research. AIDS 2000; 14(Suppl 1): S3-10.

99. Abdul-Quader A, Feelemyer J, Modi S, Stein ES, Briceno A, Semaan S, et al. Effectiveness of structural-level needle/syringe programs to reduce $\mathrm{HCV}$ and HIV infection among people who inject drugs: a systematic review. AIDS Behav 2013; 17(9): 2878-92.

100. Rotheram-Borus MJ, Swendeman D, Chovnick G. The Past, Present, and Future of HIV Prevention: Integrating Behavioral, Biomedical, and Structural Intervention Strategies for the Next Generation of HIV Prevention. Annu Rev Clin Psychol 2009; 5: 143-67.

101. Rojanapithayakorn W. The $100 \%$ Condom Use Programme in Asia. Reprod Health Matters 2006; 14(28): 41-52.
102. Cornish F, Priego-Hernandez J, Campbell C, Mburu G, McLean $S$. The impact of community mobilisation on HIV prevention in middle and low income countries: a systematic review and critique. AIDS Behav 2014; 18(11): 2110-34.

103. Pronyk PM, Hargreaves JR, Kim JC, Morison LA, Phetla G, Watts C, et al. Effect of a structural intervention for the prevention of intimate-partner violence and HIV in rural South Africa: a cluster randomised trial. Lancet 2006; 368(9551): 1973-83.

104. Altman L, Kuhlmann AKS, Galavotti C. Understanding the black box: A systematic review of the measurement of the community mobilization process in evaluations of interventions targeting sexual, reproductive, and maternal health. Eval Program Plann 2015; 49: 86-97.

105. McGowan I. An overview of antiretroviral pre-exposure prophylaxis of HIV infection. Am J Reprod Immunol 2014; 71(6): 624-30.

Received on: 05/25/2015

Final version presented on: 06/12/2015

Accepted on: 06/15/2015 